\title{
Teacher's burnout syndrome: the phenomenology of the process
}

\begin{abstract}
Introduction. The article is devoted to the phenomenology of burnout symptoms among teachers and determining their individual characteristics.

Aim. The aim was to study the phenomenology of the burnout process among teachers and to define its individual determinants.

Material and methods. The theoretical basis for the study was a burnout model described by V.V. Boyko considering the burnout as a mechanism of psychological protection of personality in response to the traumatic circumstances of the environment. The following diagnostic tools were used: the Boyko's Emotional Burnout Inventory, the Inventory on behavior and experience in the working environment by W. Schaarschmidt and A. Fischer and the individual-typological questionnaire by L.Sobchik. In order to calculate and evaluate the results, methods of mathematical statistics were applied.

Results. The results of polling 132 teachers show that more than one third of working teachers show prominent features of high level burnout. This is combined with a number of personality traits and features of behavior, and with an emotional response of the teacher to the circumstances of the working environment, what suggests the need for the development and systematic implementation of prevention programs and correction of burnout among working teachers.

Conclusions. A significant part of the surveyed teachers show signs of burnout expressed at a significant level. Thus, the problem of psychological assistance and psychological support for working teachers remains relevant and requires the search for effective technologies and techniques for providing psychological assistance.
\end{abstract}

Keywords: burnout syndrome, the phenomenology of burnout, teacher's burnout, job stress, Boyko's Emotional Burnout Inventory.

DOI: $10.1515 /$ pjph-2017-0014

\section{INTRODUCTION}

From the late 70 s to early 80 s of the XX century, the scientific psychological world could observe a wave of research and discussionconcerning the subkect of the "burnout syndrome" - a psychogenic disorder that occurs in the professional activities of individuals. Today, numerous studies have proven that representatives of all "person-person" professions [1-4] suffer from burnout syndrome, and it has been included in the International Classification of Diseases, rev. 10 (Chapter XXI, Section "Problems related to life management difficulty", number Z73.0).

The first place in the number of published works on the issue of burnout belongs to the study of burnout in the profession of teacher $[1,5]$. The studies conducted in different countries of the world show that teachers constitute a special "risk group" [1,6-9]. The main factors causing burnout among teachers include high level of overloading, both emotional and intellectual, significant level of responsibility for students combined with low moral and material compensation (for example, in Ukraine the teacher's job is among the low-paid ones).

Relevance of the study of the burnout syndrome among teachers is related to the fact that the negative effects of burn- out are felt not only by the teachers, but also by their students. The teacher's psychological state affects the quality of the whole educational process, which in the case of teacher's burnout is formal.

\section{AIM}

The purpose of the article is to study the phenomenology of the burnout process among teachers and to define its individual determinants.

\section{MATRIAL AND METHODS}

The psychological state of burnout was described in 1974 by H. Freudenberger, an American psychiatrist who, while working in a drug addiction clinic, noticed that after a year of work in this clinic, volunteers began to complain about the loss of motivation to work, about the appearance of anxiety and depression, and about a general feeling of exhaustion [3]. He described this as a staff burnout phenomenon, indicating that it is a process accompanied by a progressive sense of energy exhaustion and loss of motivation to work. 
The scientific study of this phenomenon today is carried out using several models. One of the most popular models is the model of K. Maslach, where burnout is considered as a combination of three symptoms (burnout components): emotional exhaustion, depersonalization, and reduction of professional accomplishment $[4,9]$. The emotional exhaustion means the state of emotional devastation and fatigue caused by the stress of interpersonal contacts during the performance of professional duties at work. Depersonalization is conceptually described as a response to those aspects of work or environment that characterize it as bureaucratic, impersonal, and rigid. Depersonalization is characterized by cynicism, detachment in relation to the organization where the person works and to its clients. The sense of reduction of professional accomplishment is described as confidence in individual's own incompetence; the researchers call the perception of its own inefficiency the core of this process.

In our study we relied on the burnout model proposed by V.V. Boyko [10]. The methodological basis for the concept of burnout by V.V. Boyko was a combination of the classical theory of general adaptation syndrome developed by H. Selye [11] and the theory of burnout syndrome by K. Maslach [4,9].

He defines the emotional burnout as a personality-generated mechanism of psychological protection in the form of complete or partial exclusion of emotions in response to the selected psycho-traumatic circumstances [10] V.V. Boyko says that emotional burnout on one hand allows a person to save his/her own energy resources (emotional and intellectual), and on the other hand, negatively affects the health of the person (both somatic and mental), and his/her activities.

Phases of the development of the emotional burnout syndrome in the concept of V.V. Boyko are similar to the phases of development of the general adaptive syndrome. Tension serves as a starting mechanism that triggers the formation of the emotional burnout. Stress is determined by the stable intensity of the stress factors, which are both positive and negative moments of activity. The next phase is the phase of resistance, or resistibility to psycho-traumatic factors. However, in fact, the resistibility to increasing stress and burnout begins from the moment of jitteriness. This is natural, as a person deliberately or unknowingly strives for psychological comfort and for reducing the pressure of the surrounding circumstances. The phase of exhaustion is characterized by more or less pronounced decrease in the total energy tone and weakening of the nervous system. Emotional protection in the form of "emotional burnout" becomes an integral attribute of the individual. V.V. Boyko believes that the transition of reactions from the level of emotions to the level of psychosomatics suggests that emotional defense in the form of a burnout syndrome itself cannot cope with the loads, and the energy of emotions is redistributed among other subsystems of the organism. In his opinion, this is how the body saves itself from the destructive power of emotional energy [10].

Consequently, this construct formed the basis for studying the burnout among working teachers. The work of a school teacher in Ukraine is characterized by high emotional stress, responsibility for life and health of pupils, combined with low payment for this work. During the working day, the teacher is constantly in the close contact with a large number of people: students, colleagues, and school administration. It should be noted that the study of burnout in this professional group was and remains relevant in different countries of the world, as teachers, along with medical staff and professionals who are engaged in occupations such as "human service careers", are among those who are at risk to "burn out". The analysis of studies on the issue of teachers' burnout allows us to state the ambiguity of the results of phenomenology and the specifics of the influence of a factor, depending on certain organizational working conditions (for example, whether a teacher works with children who have development disorders, or children whose development is within the age limits, etc.), on the culture features and other factors.

In order to study the features of the burnout experience by teachers, 132 teachers of secondary schools, high schools and junior high schools were surveyed. The age of the respondents ranged from 19 to 67 years. The average age was 40.7 years.

To achieve the goal, the psychological testing was carried out and the following diagnostic methods were used: Boyko's Emotional Burnout Inventory, Inventory of behavior and work-related experiences (German: "AVEM - Arbeitsbezogenes Verhaltens und Erlebensmuster'). Methods of mathematical statistics were used to calculate data.

Boyko's Emotional Burnout Inventory [10] contains 84 questions which are grouped into three scales, making it possible to diagnose the formation of each of the three burnout phases: stress, resistibility, and exhaustion. Each scale is divided into four subscales. The total score obtained for each of these subscales allows diagnosing the presence and extent of the severity of the symptoms (signs) characteristic for each burnout phase. Thus, for the phase of tension, the following attributes are evaluated: experience of traumatic circumstances of professional activity, dissatisfaction with oneself (chosen profession, occupied position, or specific duties), feeling of "being trapped in a cage", anxiety and depression. For the phase of resistance the following attributes are evaluated: inadequate selective response, emotional and moral disorientation, expansion of the sphere of emotions saving (in communication with relatives), reduction of professional duties that require emotional expenses. For the phase of exhaustion the following attributes are evaluated: emotional deficiency, emotional isolation, person's detachment, psychosomatic and psycho-vegetative disorders.

The Inventory of behavior and work-related experiences by W. Schaarschmidt and A. Fischer [12] is a multifactorial diagnostic tool consisting of 66 statements combined in 11 scales for six statements in each, reflecting the human response to the requirements of the professional environment and the behavior patterns that are formed on the basis of these reactions.

Personality characteristics were diagnosed by the Individual and typological inventory by L.Sobchik [13].

The paper used the Pearson correlation analysis (r), finding the levels and frequency of the severity of the symptoms in terms of percentage points.

\section{RESULTS}

The study by the method of the Boyko's Emotional Burnout Inventory showed the following results.

In general within the sampling, the average rate of burnout is as follows: for the tension phase -38.7 points, for the resistance phase -51.7 points, which indicates the process of data generation of the two features. For the exhaustion phase, the index is 33.2 points resistibility, indicating that the index is not formed. 
Estimation of the level of burnout phases for each of the subjects gave the following results. The stress phase is being formed or is already formed in $48 \%$ of the respondents.

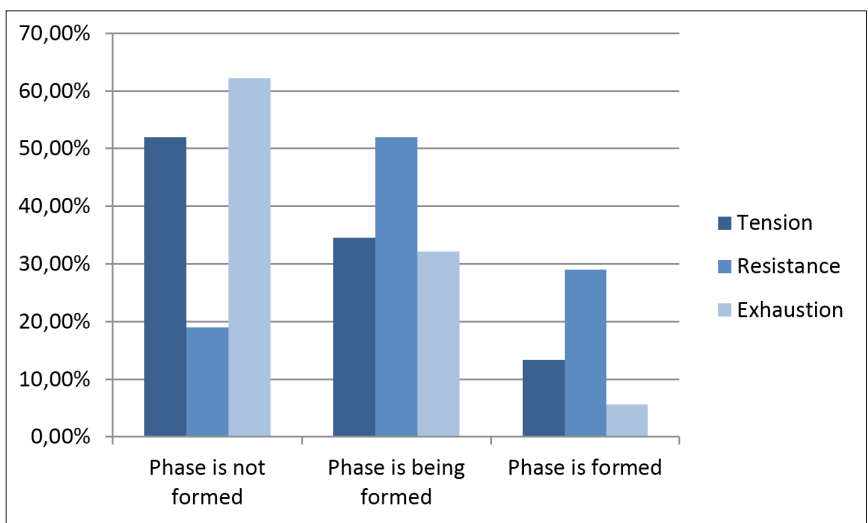

FIGURE 1. Estimation of burnout syndrome among teachers according to the Boyko's Emotional Burnout Inventory (N=132).

Phenomenology of the burnout symptoms at the tension phase is characterized by the following.

The dominant phenomenon ("symptom", according to the terminology of the author of the inventory) is the emotional response to the psycho-traumatic circumstances of the working environment (in $36.9 \%$ of the respondents this form of response is presented as the formed burnout sign, in $27.5 \%$ it is being formed). It means that the signs of a traumatic experience symptom are diagnosed in $64.4 \%$ of teachers. According to V.V. Boyko, the most striking evidence of the burnout process beginning is the increased awareness of the psychotraumatic factors of the professional activity that were either previously absent or simply not noted at a significant level for the individual. Not every person can cope with this phenomenon, so such negative experiences become an impetus for the emergence of other symptoms of emotional burnout.

When it comes to $32.6 \%$ of the respondents, they show signs of dissatisfaction with themselves, with chosen profession, position or performed duties. Such negative feelings about themselves as personalities and professionals tend to reduce self-esteem. Individual becomes more vulnerable to psychotropic factors of professional activity, what provokes further dynamics of emotional burnout.

The number of $37.1 \%$ of teachers have signs of a "stigma" symptom characterized by a sense of hopelessness, helplessness, awareness of the fact that they are governed by the circumstances. Thus, in particular, the polled teachers expressed strong dissatisfaction with the significant influence of the instructions and orders of the district education department on the school life.

As many as $44.7 \%$ of the surveyed teachers reveal signs of situational and personal anxiety, which is the most important symptom of the first phase of burnout. Among them, 19.7\% of the respondents have already formed sign of burnout, and in $25 \%$ of the respondents this form of a sign that is being formed.

\section{DISCUSSION}

Based on the obtained data, it is clear that the teachers are characterized by rather vivid expression of the symptoms of resistibility. As it can be seen from the results of the study, $81 \%$ of the respondents are characterized by an average and high degree of the resistibility phase formation $(29 \%-$ the phase is completely formed, $52 \%$ - the phase is being formed).

Regarding the symptoms of the resistibility phase, $91 \%$ of respondents use inadequate selective emotional response as a maladaptive defense strategy. It is shown that the teacher communicates with and responds to students, colleagues and other people he/she meets in the workplace, according to the mood. One day they can respond emotionally to a colleague or student, and the other, the situation is different. Such strategy is very different from the truly economic manifestation of emotions, which does not have impact on understanding the needs of students, nor repel the person from them.

As many as $57.68 \%$ of respondents use the excuse as a defense strategy to justify the fact that they do not show the necessary emotional attitude towards students and colleagues.

In $57.6 \%$ of the respondents, the use of the mechanisms of protection from emotional burnout at work and in communication with relatives is found. The respondents tell about decrease in the desire to communicate with their families, about the need to stay alone for a long time after the end of the working day.

For $60.65 \%$ of the respondents the reduction of professional responsibilities is characteristic. This symptom of emotional burnout consists the fact that the teachers are trying to reduce the time of communication with colleagues at work, and especially - with students. The teacher tries to avoid communication with students, is much less interested in their personalities and out-of-school life. That is, the teacher simply avoids those forms of behavior and communication which require high emotional response, but at the same time, it is related to their professional duties.

With regard to symptoms of exhaustion, which indicate that the person has already lost the ability to resist the stress factors that are associated with their professional activity, $38.3 \%$ of the interviewed teachers reveal the symptoms of the formation of this emotional burnout component at the significant level. According to V.V. Boyko, the appearance of exhaustion symptoms confirms the decrease in the total energy tone of the individual manifested in the emergence of symptoms of emotional and personal detachment, and psychosomatic reactions.

When it comes to $33.4 \%$ of the respondents, they show a symptom of "emotional deficiency", which is characterized by awareness of their own insolvency to a positive emotional experience regarding everything that is happening at work. The emotional deficit is manifested in the teachers' perception that emotionally they cannot enter into the students' problems.

The number of $29.55 \%$ of the respondents are characterized by a symptom of "emotional detachment", which manifests in the attempt to exclude both positive and negative emotions from the professional sphere.

The symptom of "personal detachment" (or "depersonalization") is found in $34.85 \%$ of the respondents. The sign of this symptom among the teachers is, first of all, the loss of interest in students as communication subjects.

With regard to the symptom of "psychosomatic and psychoactive autonomy", $51.52 \%$ of respondents say that they have headaches, troubles with the cardiovascular system and sleep, taking medication for improving their well-being and mood. All of this is associated with problems and difficulties at work, poor relationships with some colleagues, and significant overload at work. However, it should be noted that psychosomatic 
reactions arise in the phase of stress, in case of symptoms of anxiety, depression.

In general, sampling of 51 subjects, or $38.3 \%$ of the sampling, show a sign of all three stages of burnout at the level that suggests that this phase is being formed or is already formed. That is, a significant part of working teachers need enhanced professional psychological attention and assistance.

The analysis of the results of the Inventory of Behavior and Work-related Experiences by W. Shaarschmidt and A. Fischer, supplemented the picture of the burnout phenomenon of the teachers. During the analysis, it turned out that the signs of burnout correlate with a number of indicators describing the behavior and attitude of a person to professional activity.

Thus, the tendency to abandon the activity in case of failure situation, positively correlates with the severity of the three phases of burnout: tension phase $(\mathrm{r}=0.403, \mathrm{p} \leq 0.001)$, resistance phase $(r=0.427, p \leq 0.001)$, exhaustion phase $(r=0.409$, $\mathrm{p} \leq 0.001)$, as well as with the general burnout index $(\mathrm{r}=0.480$, $\mathrm{p} \leq 0.001$ ).

An active strategy for problem solving, an optimistic setup for problems and tasks arising at work has inverse correlations with burnout: resistance phase $(r=-0.296, p \leq 0.05)$, exhaustion phase $(\mathrm{r}=-0.235, \mathrm{p} \leq 0.05)$ and general burnout index $(\mathrm{r}=-0.258$, $\mathrm{p} \leq 0.05)$.

The maintenance of the internal balance and rest also has inverse correlation relations with the components of the burnout: tension phase $(\mathrm{r}=-0.221, \mathrm{p} \leq 0.05)$, resistance phase $(\mathrm{r}=-0.19, \mathrm{p} \leq 0.05)$, exhaustion phase $(\mathrm{r}=-0.206, \mathrm{p} \leq 0.05)$, and general burnout index $(r=-0.284, p \leq 0.05)$.

A number of indicators of the inventory measure the emotional attitude to work and there is also a dependence on the degree of burnout manifestation.

Thus, the sense of success in professional activity is inversely correlated with the indicators of burnout in its three phases: tension phase $(\mathrm{r}=-0.274, \mathrm{p} \leq 0.05)$, resistance phase $(\mathrm{r}=-0.250, \mathrm{p} \leq 0.05)$, exhaustion phase $(\mathrm{r}=0.206, \mathrm{r} \leq 0.05)$ and general burnout index $(r=-0.284, p \leq 0.05)$.

Similarly, the inverse correlation relationships were found with the experience of life satisfaction and burnout: resistance phase $(\mathrm{r}=-0.255, \mathrm{p} \leq 0.05)$, exhaustion phase $(\mathrm{r}=-0.229$, $\mathrm{p} \leq 0.05)$, and general burnout index $(\mathrm{r}=-0.249, \mathrm{p} \leq 0.05)$.

The burnout was not related to the feeling of the presence or absence of social support (the correlation coefficients do not reach the level of statistical significance). This result was unexpected, since in multiple studies this factor is considered to be counteracting the development of burnout.

That is, teachers with a high level of burnout, are assessed by the method of V.V. Boyko, characterized by low subjective value of activity, the tendency to refuse activity in a situation of failure, by emotional tension and instability in the working environment, by a feeling of inefficiency and dissatisfaction with carrier growth and, finally, by frustration and existential despair.

Instead, teachers with a low level of burnout are characterized by satisfaction with life, success in professional activity, inner calm and balance, active strategy to overcome problems and high subjective values of activity.

The correlation analysis between the severity of the signs of burning and the personal properties of the subjects showed the following results.

The spontaneity at the significant high level inversely correlates with the tension phase $(\mathrm{r}=-0.260, \mathrm{p} \leq 0.05)$, resistance phase $(r=-0.314, p \leq 0.05)$, exhaustion phase $(r=-0.290, p \leq 0.05)$ and general burnout index as a whole $(r=-0.334, p \leq 0.05)$. Anxiety has the relevance of the correlations of the tension phase $(r=0.297, p \leq 0.05)$, resistance phase $(r=0.278, p \leq 0.05)$ and general burnout index $(r=-0.228, p \leq 0.05)$. Sensitivity positively correlates with the parameters of the tension phase $(\mathrm{r}=0.209$, $\mathrm{p} \leq 0.05$ ). Rigidity (which is manifested by the features of subjectivity, rigid attitudes, persistence of personality, prone to pedantry and suspicion) has inverse correlation relations with resistance phase $(\mathrm{r}=-0.232, \mathrm{p} \leq 0.05)$ and general burnout index $(r=-0.207, p \leq 0.05)$. That is, the presence of such personality traits as high anxiety and sensitivity will contribute to the burnout in the professional activities of the teacher. Most likely, such connection is due to the fact that these features make the person sensitive to those features that are inherent in the teacher's work and cause the formation of protection mechanism in the form of burnout. Spontaneity and rigidity will allow avoiding the burnout that essentially characterizes the personality as intrusive in their own subjectivity and selfassertion, and aspiration to be a leader.

\section{CONCLUSIONS}

The conducted research allows the following conclusions. A significant part of the surveyed teachers $(38.3 \%$ of the respondents) show signs of burnout, expressed at a significant level. The phenomenology of burnout is manifested in a number of characteristics, which affect the quality of life of the working teacher, his/her psychological health, as well as the relations with all the participants of the educational process. Thus, the tendency to burn out is related to the low subjective significance of its activity, tendency to refuse activity in a situation of failure, emotional tension, feeling of inefficiency in the working environment, and dissatisfaction with career growth. Such personality traits as anxiety and sensitivity contribute to burnout. Thus, the problem of psychological assistance and psychological support for working teachers remains relevant and requires the search for effective technologies and techniques for providing psychological assistance.

\section{REFERENCES}

1. Vodopyanova N, Starchenkova YS. Burnout syndrome: diagnosis and prevention. 2nd ed. SPb.: Peter;2008; 336.

2. Duran AD, Pacheco NE, Pena LR. El sindrome de burnout en el ambito educativo: Una aproximacion diferencial. Apuntes de Psicologia. $2001 ; 19(2): 251-62$.

3. Freudenberger HJ. Staff Burn-Out. J Soc Iss. 1974;30(1):159-65.

4. Leiter MP, Bakker AB, Maslach C. Burnout at Work: A psychological perspective. NY: Psychology Press; 2014.

5. Kuznetsov MA, Gritsuk OV. Emotional burnout of teachers: basic laws of dynamics: monograph. Kharkov: GS Skovoroda Kharkov National Pedagogic University; 2011. p. 206.

6. Alkhrisha M. Burnout among a selective sample of American and Jordanian teachers. Dirasat, Edu Sci. 2002;29(2):405-14.

7. Pines AM. Teacher burnout: A psychodynamic existential perspective. Teachers and Teaching: Theory and Practice. 2002;8(2):121-40.

8. Badawy SM. Egyptian Teachers' Burnout: The Role of Work Environment Characteristics and Job Stress. J Business Manage Sci. 2015;3(4):101-10. [http://pubs.sciepub.com/jbms/3/4/1]

9. Maslach C, Leiter MP. Understanding the burnout experience: Recent research and its implications for psychiatry. World Psychiatry. 2016;15(2):103-11. [https://www.ncbi.nlm.nih.gov/pmc/articles/ PMC4911781/]

10. Boyko VV. The energy of emotions in communication: a look at oneself and on others. Yaroslavl: Avers Press; 2004. p.338. 
11. Selye H. Stress without distress: Translated from English. M.: Progress; 1998. p. 125.

12. Ronginskaya TI. Syndrome of burnout in social professions. Psychol J. 2002;23(3):85-95

13. Sobchik LN. Psychology of personality. Theory and practice of psychodiagnostics. SPb.: Publishing house "Rech"; 2005. p.624.
Corresponding author

Nataliya Bulatevych

Developmental Psychology Department of the Faculty of Psychology at the Taras Shevchenko National University of Kyiv

Email: bulatevich@ukr.net 